\title{
Lactose Intolerance-Old and New Knowledge on Pathophysiological Mechanisms, Diagnosis, and Treatment
}

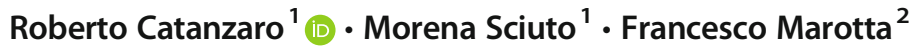

Accepted: 27 January 2021 / Published online: 5 February 2021

(C) The Author(s) 2021

\begin{abstract}
Lactose intolerance is a pathology frequently encountered today. It occurs when the activity of lactase in the intestine is reduced or absent, with consequent failure to digest lactose. The global prevalence of this clinical condition is estimated of about 57\% with instrumental methods, while the real prevalence exceeds $65 \%$. The absence of lactase determines both the excessive osmotic load in the small intestine and the fermentation of lactose by the bacterial flora with consequent production of short-chain fatty acids and gas. This latter process is responsible for the onset of symptoms associated with lactose intolerance (abdominal pain, bloating, flatulence, etc.) which arise after the intake of lactose. Several studies have shown an increased risk of developing various pathologies for lactose-intolerant subjects (some types of cancer, osteoporosis, etc.). Therefore, it is essential to diagnose and properly treat this pathology. Various options exist for diagnosing lactose intolerance: Hydrogen Breath Test, genetic test, Quick Lactose Intolerant Test, Lactose Tolerance Test, Gaxilose Test. Like diagnostic methods, there are several options for treating intolerance. In addition to a food restriction, the use of exogenous enzymes and/or probiotic and the selection of milk containing specific types of beta-caseins less correlated to the appearance of gastrointestinal symptoms are very useful. The aim of this review is to illustrate the main and most modern diagnostic and therapeutic choices for lactose intolerance currently available.
\end{abstract}

Keywords Lactose intolerance $\cdot$ Hydrogen Breath Test $\cdot$ Lactase $\cdot$ Probiotics $\cdot$ Hypolactasia

\section{Introduction}

Lactose malabsorption or hypolactasia is a common condition caused by a low lactase activity, with consequent reduction of lactose absorption. Lactose intolerance occurs when the malabsorption causes symptoms [1].

The severity of the symptoms is subjective and depends on the amount of ingested lactose, on the concentration of lactase present in the intestinal mucosa, on the intestinal flora, on the

This article is part of the Topical Collection on Medicine

Roberto Catanzaro

rcatanza@unict.it

1 Department of Clinical and Experimental Medicine,

Gastroenterology Section, "Gaspare Rodolico" Policlinico Hospital, University of Catania, via Santa Sofia, 78 (Bld 4 - 1st floor), 95123 Catania, IT, Italy

2 ReGenera R\&D International for Aging Intervention \& San Babila Clinic, Corso Giacomo Matteotti, 1a, 20121 Milan, Italy gastrointestinal motility, and on the individual sensitivity in the perception of symptoms [2].

\section{Epidemiology}

Lactose intolerance diagnosed with instrumental methods has a global prevalence of about $57 \%$. Instead, it is estimated that the real prevalence exceeds $65 \%$. This condition has a prevalence of about $50 \%$ in South America, Africa, and Asia. In the USA, the prevalence is $15 \%$ among whites, $53 \%$ among Mexican-Americans, and $80 \%$ in the Black population. In Europe, the prevalence is about $28 \%$, with variable percentages between the North and South of the continent. Indeed, it varies from 2\% in Scandinavia to about 70\% in Sicily [3].

\section{Lactose Biochemistry and Metabolism}

Lactose is a disaccharide composed of D-galactose bound to $\mathrm{D}$-glucose. It is present in dairy products. The concentration of 
lactose in a mother's milk is $7.2 \mathrm{mg} / 100 \mathrm{ml}$ whereas in a cow's milk it reaches only $4.7 \mathrm{mg} / 100 \mathrm{ml}$ [4].

Lactose is synthesized in the mammary gland from glucose and galactose by the action of lactose synthetase. It is an enzyme which has two subunits: one with galactosyltransferase activity and other with regulatory actions, which catalyze the union of galactose and glucose to form the disaccharide [5].

For its use in the human body, lactose must be hydrolyzed by lactase enzyme, that is, present on intestinal mucosal surface. From week 8 of gestation, lactase activity can be detected at the mucosal surface in the human bowel. This activity increases until week 34 and lactase reaches its maximum peak at birth. The ability to digest lactose during the period of breastfeeding is essential to the health of the infant. This importance has been demonstrated by the fact that one of its congenital deficiency is fatal if not recognized very early after birth. Lactose hydrolyzing hesitates with the formation of the two monosaccharides, glucose and galactose, which are absorbed by active transport mediated by Sodium-Glucose Linked Transporter 1 (SGLUT-1). The latter is a membrane protein that co-transports glucose or galactose and two ions sodium $\left(\mathrm{Na}^{+}\right)$from the intestinal lumen to enterocyte cytosol. Subsequently, the monosaccharides pass from the cytosol to the blood by Glucose Transporter 2 (GLUT-2), present on the enterocyte membrane $[5,6]$.

A deficiency of lactase leads to a reduction in the absorption of lactose present in the intestinal tract and this can cause the appearance of the symptoms (Fig. 1). First, the excessive osmotic load increases the intestinal water content. Second, lactose is readily fermented by the colonic microbiome leading to production of short-chain fatty acids and gas (mainly hydrogen - $\mathrm{H}_{2}-$, carbon dioxide - $\mathrm{CO}_{2}-$, and methane - $\mathrm{CH}_{4}-$ ) [7].

The amount of ingested lactose that causes the appearance of symptoms is variable from one individual to another and it is dependent on several factors: the dose consumed, residual lactase expression, ingestion of lactose with other dietary components, gut-transit time, small bowel bacterial overgrowth, and also composition of the enteric microbiome [8].

\section{Genetic of Lactase}

Lactase is encoded by a gene, LCT, of about $50 \mathrm{~kb}$ and localized on chromosome 2 (locus 2q21). Gene has 17 exons and it encodes an mRNA from which is obtained a pre-protein that is processed to a smaller protein, which has one active site. Lactase expression is restricted to the enterocytes of the small intestine. In particular, it is expressed at the highest levels in the mid-jejunum. Two possible polymorphisms of this gene were sequenced. The first is C/T-13910, located at $14 \mathrm{~kb}$. It is based on the presence of one cytosine $(\mathrm{C})$ or one thymine $(\mathrm{T})$ in position 13910 . The variant $\mathrm{C} / \mathrm{C}$ is related to the non persistence of lactase; instead, the variants $\mathrm{C} / \mathrm{T}$ or $\mathrm{T} / \mathrm{T}$ are expression of lactase persistence. The second polymorphism is G/A-22108, located at $22 \mathrm{~kb}$. It is based on the presence of one guanine $(\mathrm{G})$ or one adenine $(\mathrm{A})$ in position 22108 . The variant $G / G$ is related to the non persistence of lactase, while the variants $\mathrm{G} / \mathrm{A}$ or $\mathrm{A} / \mathrm{A}$ are expression of lactase persistence [9].

However, in other countries of the world, more polymorphisms have been identified, for example, in Africa and in Middle East have been found: C/G-13915, G/C-14010, and T/G-14009 [10].

In addition to gene mutations, other mechanisms may be responsible for lactose intolerance. In fact, epigenetic modifications in DNA and histone proteins can contribute to lactase non persistence [11].

\section{Clinical Conditions}

Typical symptoms of lactose intolerance are abdominal pain, bloating, flatulence, diarrhea, borborygmi, and in some cases, constipation, nausea, and vomiting. They usually begin around $1 \mathrm{~h}$ after the intake of lactose, but they may appear earlier or later [12].

In subjects with lactose intolerance, gas is produced because lactose is not digested and absorbed in the small bowel, and it is fermented by intestinal flora. Some studies have shown that there are minimal or no differences between gas production in lactose malabsorbers and in lactose intolerance. Therefore, it is the sensitivity to bowel distension to determine the appearance of symptoms, in this case swelling and abdominal pain. In addition, other factors that influence the bloating are abnormal colonic flora, small bacterial overgrowth, and impaired absorption of substrates [13].

Moreover, other extra-intestinal symptoms have been described in patients with lactose intolerance, for example, memory deterioration, cephalalgy muscoskeletal pain, depression, anxiety, ulcers in the oral mucosa, and heart rhythm disorders. The cause could be the toxic effects of chemical substances such as acetone, acetaldehyde, ethanol, and peptides which are formed in the course of maldigestion and malabsorption of lactose [5, 14].

\section{Diagnostic Process}

Various options exist for diagnosing lactose intolerance.

\section{Hydrogen Breath Test}

The formal test which is commonly used in patients suspected of having lactose intolerance is the $\mathrm{H}_{2}$ Breath Test (HBT). It has become widely available and it is often used for diagnosis 

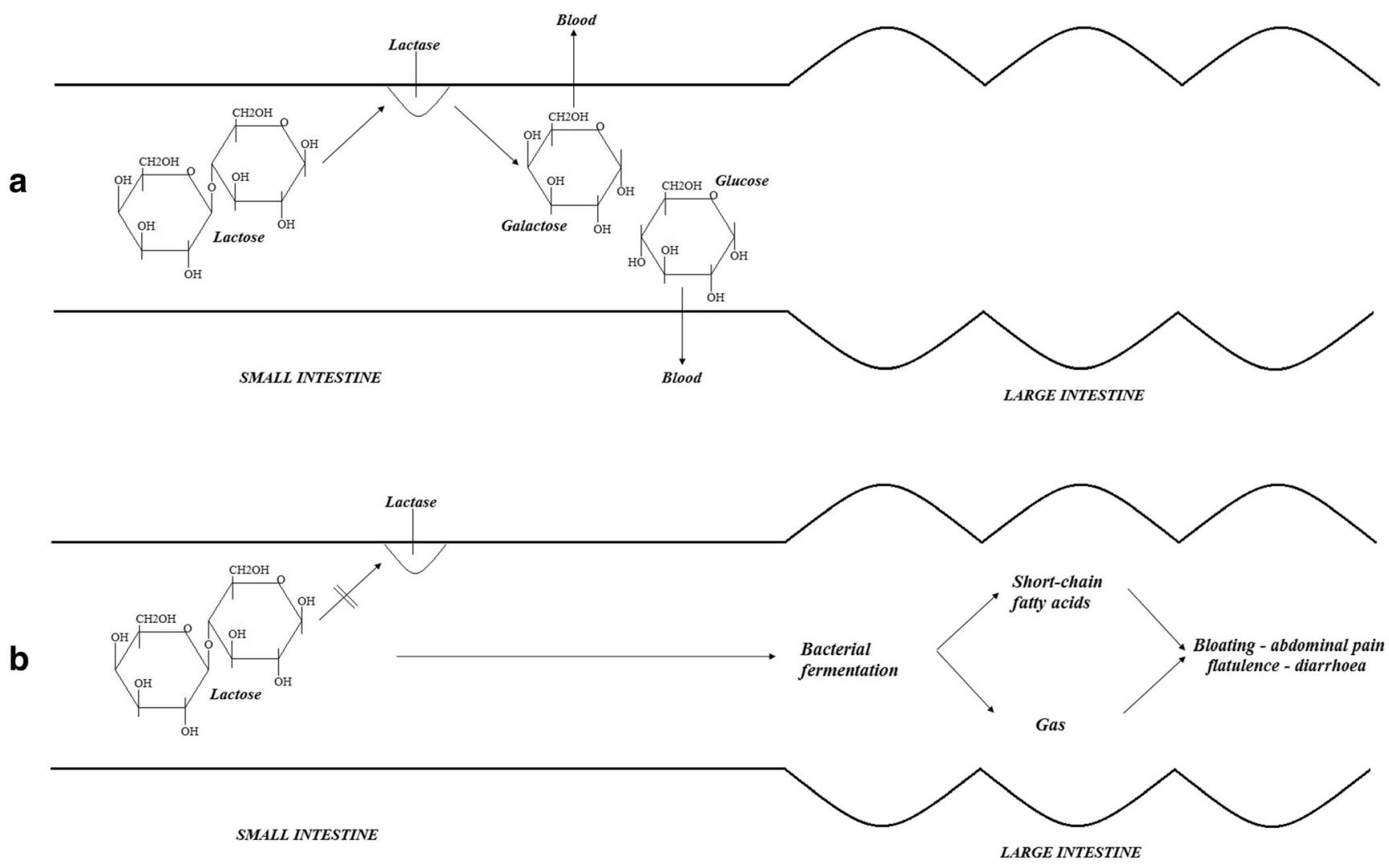

Fig. 1 a Normal digestion of lactose in the presence of the lactase. b Lactose intolerance due to lactase deficiency and subsequent onset of symptoms

of lactose intolerance. The test is based on the principle that undigested lactose undergoes fermentation by the microbial flora, with subsequent gas production, including hydrogen. It involves ingestion of 25 to $50 \mathrm{~g}$ of lactose and the measurement of hydrogen every $15 \mathrm{~min}$ for 3-6 h. An increase in breath hydrogen concentration greater than $20 \mathrm{ppm}$ (parts per million) over baseline, after lactose ingestion, suggests hypolactasia [15].

A disadvantage of the test is its long duration (from 3 to 6 h) and the high number of measurements to be performed during this time (every 15 min for a total of 12-24 measurements). Recently, Yang et al. have proposed a protocol (FourSample Lactose Hydrogen Breath Test, 4SLHBT) that provides only 4 measurements (at $0 \mathrm{~min}, 90 \mathrm{~min}, 120 \mathrm{~min}$, and $180 \mathrm{~min}$ ). They found a high concordance between the classic test and 4SLHBT. All this translates into better patient compliance, the possibility of reducing waiting lists in public hospital centers since in this way more people can perform the breath test in the same session, and a reduction in health care costs with a minor consumption of medical resources. Therefore, this protocol could be proposed as a standard for performing the breath test [16].

HBT is positive in $90 \%$ of patients with lactose malabsorption and false negatives can also be detected. A first explanation is given by the presence of bacteria that do not produce hydrogen but methane $\left(\mathrm{CH}_{4}\right)$. Therefore, Houben et al. conducted a study which showed that the measurement of $\mathrm{CH}_{4}$, in addition to that of hydrogen, involves an increase in the diagnostic accuracy of the breath test. In this way, it is possible to diagnose lactose intolerance even in those subjects with a bacterial flora that does not produce hydrogen [17]. Also according to Rojo et al., this method could be applied to identify intolerant subjects with normal $\mathrm{H}_{2}$ excretion, even if in their study a greater number of intolerant was not detected using the measurement of $\mathrm{CH}_{4}$ [18].

Other factors that can cause false-negative values are slow orocoecal transit, exercise, and all those conditions that affect the normal bacterial flora, such as recent use of oral antibiotics, abuse of laxatives, or invasive procedures that require preparatory bowel cleansing with enemas. Even the use of probiotics should be avoided before the test is performed, since these drugs cause an alteration of the intestinal bacterial flora [19].

Instead, factors that can determine false-positives are previous use of aspirin or proton pump inhibitors, and smoking (since the combustion of tobacco causes an increase in gases, including hydrogen). Also some foods (for example, beans, corn, white wheat, potatoes, oats) can cause an increase in the production of hydrogen and, therefore, a greater excretion of this gas with breath. In these cases, the increase in hydrogen may not be related to a lactose intolerance [20,21]. 
Regarding the costs of HBT, these depend mainly on the type of preparation used, the execution time, and the cost of the disposable materials that are chosen. In Italy, the cost of the analyzer varies between $€ 10,000$ and $€ 18,000$, since two types of machines are available: those that use a solid-state sensor and those that use an electrochemical sensor. The first are expensive and not able to detect alterations of concentration of a single gas, even if some of these machines have been modified so as to be able to detect the alterations of one or two gases. Those which use an electrochemical sensor represent the gold standard today. In Italy, the cost of HBT is around $€ 30.29$ in public hospitals [22, 23].

\section{Genetic Test}

In response to the hypotheses put forward over time regarding the genetic predisposition to lactose intolerance, polymorphisms of the gene that codes for lactase predisposing to this intolerance have been identified [24]. Considering this knowledge, a method that can be used for the diagnosis of lactose intolerance is the genetic test, which consists in the isolation of DNA through a blood sample and the subsequent analysis of polymorphisms LCT-13910C $>$ T and LCT-22018G $>$ A. However, this test has some limitations. In fact, the presence of a predisposing polymorphism $(\mathrm{C} / \mathrm{C}$ or $\mathrm{G} / \mathrm{G})$ does not allow us to predict if and when intolerance will develop. Moreover, in the presence of a symptomatology suggestive of lactose intolerance, a negative result of the genetic test does not allow to identify a possible secondary intolerance, while it is important to distinguish a primary hypolactasia from a secondary one, in order to undertake an appropriate therapeutic pathway. Instead, the genetic test could be performed after HBT in order to predict whether there is a primary or secondary intolerance [25].

Then, as proposed by Tomczonek-Moruś et al., genetic testing would be preferable in subjects who cannot perform HBT. In fact, they found a significant correlation between a positive HBT and the presence of the aforementioned polymorphisms [26].

\section{Quick Lactose Intolerant Test}

Quick Lactose Intolerant Test consists in execution of mucosal biopsies at the post-bulbar duodenum level and their subsequent incubation with lactose on test plate. This incubation aims to verify the presence or absence of lactase activity. If lactase activity is present, a dark blue-colored reaction occurs; if there is a slight hypolactasia, there will be a light blue; if no staining develops, this result will be indicative of severe hypolactasia [27].

Ojetti et al. showed that this test could be used when the common HBT proves to be negative despite the symptoms instead of the genetic test. In fact, they have found an agreement between the Quick Test and the HBT of $81 \%$ [28].

Also Tsadok Perets et al. found a high agreement between HBT and the Quick Test regarding intolerant subjects with positive HBT results. In these patients, in fact, a null or reduced lactase activity was detected in intestinal biopsies. However, in the case of subjects who tested negative for HBT, the agreement between the two tests was much lower. In fact, many patients with HBT negative results had a bioptic picture of hypolactasia. Therefore, from the conclusions of this study, it can be deduced that the execution of the Quick Test is useful only in the case of a negative result of HBT, since the Quick Test is an invasive test that can be avoided in the case of a positive HBT [29].

Moreover, this exam can also exclude secondary form of lactose intolerance as celiac disease, but although it has a high sensitivity, the Quick Test has limitations. Among these limitations is the size of biopsies which, if larger or shorter than 2 $\mathrm{mm}$, may give false-negative or false-positive hypolactasia, respectively, due to patchy expression of lactase. Another limit is the invasiveness and high cost of the endoscopic method. Moreover, since it is a bioptic examination, it is conditioned by the coagulation and the patient's clinical conditions. Furthermore, the execution of the incubation of the samples must be carried out quickly and this requires the presence of a laboratory technician in the endoscopy room. This test could be used in the case of patients for whom there are other indications for an endoscopic examination $[8,30]$.

\section{Lactose Tolerance Test}

Lactose Tolerance Test (LTT) involves the administration of $50 \mathrm{~g}$ of lactose and the glycaemia dosage before lactose intake and after $30 \mathrm{~min}, 60 \mathrm{~min}$, and $120 \mathrm{~min}$ based on plasmaglucose dosage after lactose ingestion. The digestion of lactose determines the elevation of blood glucose: the absence of such increase indicates failure absorption of lactose. This test is rarely performed due to low sensitivity and specificity. In fact, false-positive and false-negative test results occur in $20 \%$ of normal subjects because of the influence of variable gastric emptying and glucose metabolism [15, 31].

According to Goshal et al., Lactose Tolerance Test could be used in association with HBT or even alone in centers where it is not available. In fact, they have demonstrated a validity of this test comparable to the breath test. One of the advantages of the LTT is the possibility of diagnosing lactose intolerance even in subjects who are negative for HBT due to a bacterial flora that does not produce hydrogen. However, an important limitation is represented by diabetes mellitus. In fact, in diabetic patients, there may be an increase in blood glucose levels after ingesting lactose, even in the presence of intolerance [32]. 


\section{Gaxilose Test}

This is a new non-invasive test that consists of administration of Gaxilose (4-O- $\beta$-D-galactopyranosyl-D-xylose), a synthetic disaccharide provided with a structure similar to lactose. Like the latter, Gaxilose is also metabolized by lactase in the intestine. From this process, they derive a molecule of galactose and one of xylose, which will then be absorbed by enterocytes. Subsequently, xylose will be measurable in the blood and urine, through which its excretion is carried out. By measuring the amount of xylose in the blood and urine, it will be possible to quantify lactase activity [33].

This is not currently marketed and the execution costs are not known. With phase IV of a randomized controlled trial, Monsalve-Hernando et al. compared the results obtained from the Gaxilose Test and from HBT, demonstrating a noninferiority of the Gaxilose Test compared to HBT. Therefore, they propose the Gaxilose Test as a valid diagnostic choice, since they were not detected moderate-severe, but only mild adverse effects. Contraindications to the examination are currently unknown, but could be inferred from the exclusion criteria considered in the study, among these: pregnancy or lactation, diabetes mellitus, portal hypertension, alteration of glomerular filtration, recent use of some drugs (antibiotics, aspirin, or indomethacin). In practice, contraindications that normally exist for most diagnostic tests performed today. Moreover, compared to the other tests used today for the diagnosis of lactose intolerance, the Gaxilose Test is easy to use, it does not cause discomfort to the patients, and it is a quantitative test $[34,35]$.

Domínguez Jiménez et al. compared the results obtained from the Gaxilose Test and from the shortened Lactose Tolerance Test (sLTT) and their conclusions are that the Gaxilose Test has a diagnostic accuracy similar to sLTT and it has the advantage of being non-invasive and well tolerated. Furthermore, they performed the genetic test on some patients in the study and highlighted a high concordance between the results of the two tests. In particular, this concordance (expressed with $p$ value) was greater if the cut-off of the amount of xylose in urine considered pathological was shifted from $37.87 \mathrm{mg}(p<0.01)$ to $35.50 \mathrm{mg}(p<0.001)$ [36].

Thus, the Gaxilose Test could be considered the new gold standard for the diagnosis of lactose intolerance, but further studies are needed to reach this conclusion.

\section{Treatment}

Typically, management of primary lactose intolerance consists of two possible clinical choice: alimentary restriction and drug therapy. The usual behavior for this condition is the avoidance of milk and dairy products from the diet. However, as previously mentioned, dairy foods provide calcium, protein, magnesium, and other minerals and substances that are essential for preventing various diseases and ensuring different physiological functions, such as bone remodelling. The avoidance of all dairy products in patients with lactose intolerance is no longer recommended. Most people with lactose intolerance can tolerate up to $12-15 \mathrm{~g}$ of lactose per day. Strategies can be implemented to increase tolerance of lactose in these patients [12, 37].

People with lactose intolerance should be encouraged to restrict rather than avoid lactose. So they can maintain dairy products in the diet without losing the benefits associated with these foods. An available strategy for the management of patient with this intolerance contemplates:

1- Temporary lactose-free diet to obtain remission of symptoms

2- Gradual introduction of cow milk (from 30 to $250 \mathrm{ml} /$ day) which should be consumed together with other foods to slow release of lactose in the small intestine

3- Consumption of aged cheese, which contains a low share of lactose

4- Consumption of lactose-reduced milk products, which are nutritionally identical to milk products

5- Consumption of fermented products like yogurt, that are also a source of probiotics and prebiotics, and both exert beneficial effects on gastrointestinal microflora $[12,38$, 39]

Enzyme supplementation therapy with lactase from nonhuman sources to hydrolyze lactose is another important approach. The intake of exogenous lactase is expected whenever foods containing lactose are ingested. This enzymatic compound is obtained from yeast (Kluyveromyces lactis) or fungi (Aspergillus oryzae, Aspergillus niger) and it is able to break down lactose into glucose and galactose to allow a better absorption. Administration of exogenous lactase as pills has been used to treat lactose intolerance in children, adolescents, and adults with extremely good results in terms of improving the clinical picture [40, 41]. However, not all clinical studies that have been performed to evaluate the efficacy of exogenous lactase have led to satisfactory results.

Montalto et al. found a reduction in $\mathrm{H}_{2}$ excretion in intolerant patients who had taken exogenous lactase obtained from $K$. lactis. They also achieved an improvement in the clinical picture of these patients, showing that exogenous lactase represents a valid therapeutic approach in lactose intolerance [42].

Ojetti et al. conducted a randomized clinical trial to compare the effects of exogenous lactase (tilactase) and those of a probiotic containing Lactobacillus reuteri. The patients in their study, who were diagnosed with lactose intolerance by HBT, were divided into 3 groups: one group administered the tilactase, the second group administered the probiotic with 
L. reuteri, and the third group administered the placebo. After treatment, patients were re-placed on HBT. What emerged from this clinical study is that both the probiotic and the tilactase caused a reduction in the amount of hydrogen excreted. However, this reduction was clearly more marked in the case of the tilactase. Symptoms that had been taken into account at the beginning of the study (bloating, abdominal pain, flatulence, diarrhea) also improved in both groups (tilactase group and $L$. reuteri group), but the improvement was greater for patients of tilactase group. Therefore, according to Ojetti et al., the use of exogenous lactase is useful for the treatment of lactose intolerance, also to avoid the risk of osteoporosis connected to the lack of milk and dairy products intake. On the other hand, even the administration of this probiotic can be advantageous, since its effects continue to be expressed even after having suspended its intake [43].

Also Ibba et al. conducted a study aimed at assessing whether the intake of exogenous lactase by lactose-intolerant subjects determined or not a change in the hydrogen excretion rate with HBT. The enzymatic compound used in this study was Beta-Galactosidase (15,000 Units) obtained from the fermentation of Aspergillus oryzae. The results of their study showed some variability. In fact, a reduction in hydrogen excretion after taking Beta-Galactosidase was recorded in $40 \%$ of patients, while in the remaining $60 \%$ of them, the amount of hydrogen excreted did not change. However, an improvement in symptoms was observed in a much higher percentage of patients and it was highlighted a non-direct correlation between the excreted hydrogen value and the severity of symptoms reported by the patient. The reason why exogenous lactase determines different effects in subjects suffering from the same type of intolerance is still not completely clear [44].

Although the results of these studies are in contrast with each other, it can be said that the administration of exogenous lactase represents, in most cases, a valid therapeutic option. Exogenous lactase does not generally determine serious adverse effects and its use is safe and effective almost always. In fact, in most of the patients, an improvement of the symptoms and therefore of the quality of the life has been found. However, other studies are needed to assess the real efficacy and the exact benefits of using exogenous lactase.

Recently clinical trials have been conducted regarding other possible approaches aimed at improving the symptomatology of lactose intolerance and better absorption of the nutrients contained in dairy products.

Various substances are contained in cow's milk, including $\beta$-casein. Two types of this protein have been identified: type A1 and type A2, which may be present in the milk individually or in combination. Type A2 is considered the original variant. In fact, the gene encoding A1 is the result of a point mutation of the gene encoding A2, with proline substitution with histidine at position 67 . At intestinal level, $\beta$-casein undergoes proteolysis and among the peptides formed by this process, there is $\beta$-casomorphin-7 (BCM-7). Higher amounts of BCM-7 are obtained from A1 type degradation than from A2 [45]. BCM-7 is a ligand of $\mu$-opioid receptors. These receptors are located in various tissues, including the gastrointestinal tract. An effect of the overproduction of BCM-7 is represented by a slowing of the intestinal transit demonstrated by a greater consistency of the stools. This observation was made by Ho et al. who detected an increased fecal consistency in subjects who had ingested milk containing A1 $\beta$-casein compared to those who had ingested milk with A2 $\beta$-casein. Furthermore, a higher intensity of abdominal pain was detected in the group of patients who had ingested type A1 [46].

Jianqin et al. conducted a comparative study between these two types of $\beta$-casein. In particular, they created two groups of 45 patients. After 14 days of washout, during which the consumption of milk or dairy products was not allowed, one group was given milk with only A2 $\beta$-casein, while the other group was given milk with the combination of A1 and A2, for 14 days. At the end of this period, all patients in the study underwent a new 14-day washout period. Later, milk containing both $\mathrm{A} 1$ and $\mathrm{A} 2$ was given to the group that had ingested milk with only A2 $\beta$-casein. Conversely, the group that had previously taken milk with the combination of $\beta$-casein was given the one containing only A2. The study found that the consumption of milk containing A1 and A2 $\beta$-casein caused a worsening of gastrointestinal symptoms, an increase in intestinal transit time, an increase in serum inflammation markers, a slowing of cognitive abilities, and an increase in elimination fecal short-chain fatty acids. All these events did not occur, however, during the administration of milk containing only A2 $\beta$-casein. Thus, the exacerbation of symptoms was related to the presence of type A1 [47]. The same conclusions were drawn from $\mathrm{He}$ et al. who conducted a study similar to the one previously illustrated. They also detected the appearance or worsening of gastrointestinal symptoms after ingesting milk containing both $\mathrm{A} 1$ and $\mathrm{A} 2 \beta$-casein, while the milk containing only the type A2 had not determined the same effects. Therefore, more than lactose, A1 $\beta$-casein causes the symptoms [48].

A possible further therapeutic approach, therefore, could be the selection of milk containing only the type A2.

Mummah et al. conducted a study aimed at determining the possible efficacy of raw milk. In fact, some studies had shown that the consumption of raw milk was associated with the reduction of atopic diseases, irritable bowel syndrome, and with the same lactose intolerance. This was a double-blind cross-over trial that involved 16 subjects who had been diagnosed with lactose intolerance via the HBT. Each participant was given 3 types of milk, each for 8 days, alternating the intake of each type of milk with a washout period. The 3 types of milk were raw milk, pasteurized milk, and non-flavored soy milk. The outcomes were evaluated by execution of HBT and the use of visual analog symptom scales at the beginning and 
at the end of each 8-day therapy. From this study, it was found that, in reality, the intake of raw milk led to a worsening of symptoms and no significant reduction in hydrogen excretion at HBT. Therefore, according to Mummah et al., the consumption of raw milk instead of the pasteurized one cannot be considered an adequate therapeutic choice for subjects with lactose intolerance [49].

Another possible therapeutic approach is represented by probiotics. Probiotics are live microorganisms which upon ingestion in sufficient concentrations can exert health benefits to the host. Hundreds of different bacteria species are the natural and predominant constituents of intestinal microbiota. Among the greatest benefits attributed to probiotics, there are improvement of gastrointestinal microflora, reinforcement of immune system, reduction of serum cholesterol, treatment of irritable bowelassociated diarrhea, and improvement of lactose metabolism $[50,51]$. The species most frequently used for the production of probiotics are Lactobacillus spp. (L. acidophilus, L. rhamnosus, L. casei, etc.), Bifidobacterium spp., and Saccharomyces boulardii. Among the various functions of the bacteria present in the intestine, there is the maintenance of constant and low levels of short-chain fatty acids, which are implicated in the genesis of symptoms, such as abdominal pain and diarrhea. The main advantage of probiotics is the absence of absolute contraindications $[52,53]$.

Pakdaman et al. conducted a clinical trial aimed at evaluating the efficacy of DDS-1 strain of lactobacillus (manufactured by Nebraska Cultures, Inc.) in patients with lactose intolerance. Their study found that the use of these probiotics, compared to placebo, was safe and reduced diarrhea, abdominal cramps, and vomit [54].

Gingold-Belfer et al. conducted a study in which a mixture of probiotics, Bio-25 (SupHerb, Israel), consisting of lactaseproducing bacteria (L. acidophilus, L. rhamnosus, L. casei, etc.), was evaluated. The result was a significant improvement in the gastrointestinal symptoms associated with lactose intolerance. There was no reduction in hydrogen excretion to HBT in the same patients who experienced improvement in symptoms. According to Gingold-Belfer et al., this probiotic formula can be considered a valid therapeutic option, mainly referring to the clinical characteristics [55].

In the clinical trial of Vitellio et al., the effects of a combination of $B$. longum, $L$. rhamnosus, and vitamin $\mathrm{B}_{6}$ on the symptoms of lactose intolerant were analyzed. The enrolled patients were divided into two groups. One group was given the preparation, while the other group received the placebo. After 30 days, the patients stopped taking one or the other product and, after a 15-day washout period, a cross-over was performed followed by 30 days of treatment. The study showed that even the association of the probiotic with vitamin $\mathrm{B}_{6}$ determines the improvement of the clinical picture of lactose intolerant. This is mainly the result of the positive modulation of the composition and metabolism of the intestinal bacterial flora by the action of the probiotic but also by the action of the vitamin $\mathrm{B}_{6}$. Therefore, although other studies will be needed to confirm this evidence, it is possible to consider the association probiotic/vitamin $\mathrm{B}_{6}$ a valid therapeutic option for lactose intolerance [56].

The bacteria contained in probiotics can also be found in foods, for example, in yogurt. In previous years, various studies have shown how the consumption of these foods, in addition to probiotics, can influence the composition and metabolism of the intestinal bacterial flora. He et al. found an increase in fecal $\beta$ galactosidase activity in lactose-intolerant subjects after 2 weeks of consumption of yogurt and probiotics. The yogurt used by these authors was a derivative of fermented milk containing both traditional yogurt strains (Lactobacillus bulgaricus and Streptococcus thermophilus) and a specific probiotic strain (Bifidobacterium animalis). Instead, probiotics contained Bifidobacterium longum. The association of yogurt and probiotics has led to an improvement in symptoms related to lactose intolerance in the patients of this study. Therefore, even the dietary approach represented by yogurt is a valid therapeutic option aimed at improving the clinical picture [57].

Also de Vrese et al. conducted a study aimed at evaluating the association between yogurt and probiotics. In this case, the yogurt contained $S$. thermophilus and $L$. delbrückii ssp. bulgaricus, while probiotics were based on Aspergillus oryzae. In this case, greater efficacy emerged in the association of yogurt and probiotics rather than in the administration of yogurt alone or only probiotics. In fact, an increase in the ability to digest lactose was observed, demonstrated by the reduction of the hydrogen excretion peak at HBT. Furthermore, an improvement in abdominal pain and flatulence has also occurred [58]. Therefore, this preparation can also be considered a valid therapeutic approach.

In addition to probiotics, prebiotics have also been considered, which are non-digestible oligosaccharides fructans and galactans [59]. Furthermore, they facilitate the development of specific bacterial strains of the intestinal flora that are beneficial to the health of the organism [60]. However, products containing less than $48 \%$ of weight/volume of prebiotics are currently marketed [61]. According to Gibson et al., the use of probiotics could lead to an improvement in health and a reduction in the risk of developing various diseases. However, it is important to include prebiotics with a healthy lifestyle and a healthy diet [62].

Savaiano et al. conducted a clinical trial to evaluate the efficacy of RP-G28 (a product containing over 95\% galactooligosaccharide) in reducing gastrointestinal symptoms in lactose-intolerant individuals. Patients in the study were randomized into two groups, one group was given RP-G28 while the other group was given a placebo for 35 days. At the end of this period, patients were encouraged to ingest products containing lactose for 30 days. Furthermore, all patients underwent HBT and a questionnaire on the evaluation of symptom severity (Patient Global Assessment), before 
Table 1 Summary table of clinical trials with preparation used, number of subjects, age, inclusion and exclusion criteria, and effect of preparation ( $L I$, lactose intolerance; $H B T$, hydrogen breath test; $I B D$, inflammatory bowel diseases; $G I$, gastrointestinal; IBS, irritable bowel syndrome; $B M I$, body mass index; ppm, parts per million; $n / a$, data is not provided)

\begin{tabular}{|c|c|c|}
\hline Authors & Preparation used & $\begin{array}{l}\text { Subje } \\
\text { [numb }\end{array}$ \\
\hline $\begin{array}{l}\text { Gingold-Belfer } \\
\text { et al. } 2019 \\
\text { [55] }\end{array}$ & BIO-25 & 8 \\
\hline $\begin{array}{l}\text { Vitellio et al. } \\
2019 \text { [56] }\end{array}$ & $\begin{array}{l}\text { Formulation of } \\
\text { Bifidobacterium } \\
\text { longum BB536, } \\
\text { Lactobacillus } \\
\text { rhamnosus HN001, } \\
\text { and vitamin B6 }\end{array}$ & 23 \\
\hline $\begin{array}{l}\text { He M et al. } \\
2017 \text { [48] }\end{array}$ & $\begin{array}{l}\text { Milk containing only A2 } \\
\beta \text {-casein vs milk con- } \\
\text { taining A1 and A2 } \\
\beta \text {-casein }\end{array}$ & 600 \\
\hline
\end{tabular}

Jianqin S et al. Milk containing only A2 45

2016 [47] $\quad \beta$-casein vs milk containing $\mathrm{A} 1$ and $\mathrm{A} 2$ $\beta$-casein

$\begin{array}{ll}\begin{array}{c}\text { Pakdaman M } \\ \text { et al. }\end{array} & \begin{array}{r}\text { DDS-1 strain of } \\ \text { Lactobacillus }\end{array} \\ 2016[54] & \text { acidophilus }\end{array}$

et al acidophilus
Ibba et al. 2014 Beta-Galactosidase [44] obtained from Aspergillus oryzae

$\begin{array}{cc}\begin{array}{c}\text { Mummah S } \\ \text { et al. 2014 }\end{array} & \text { Raw milk } \\ \text { [49] } & \\ & \\ \text { De Vrese et al. } & \begin{array}{c}\text { Combination of acid } \\ \text { lactase from } \\ \text { Aspergillus oryzae } \\ \text { and yogurt bacteria }\end{array}\end{array}$

20-50 Self-reported LI and Eating disorder; metabolic digestive discomfort after consuming traditional milk
26-68 Self-reported intolerance to traditional milk; mild or moderate digestive discomfort after milk consumption

30-75 Healthy volunteers; BMI between 18 and $35 \mathrm{~kg} / \mathrm{m} 2$; Lactose Challenge Test 6-hour Symptom Score > 10
18-65 Symptoms of LI after ingestion of milk; HBT positive

\begin{tabular}{|c|c|}
\hline$>18$ & $\begin{array}{l}\text { Patients with peak } \\
\text { hydrogen } \\
\text { concentrations } \\
\text { greater than } \\
25 \mathrm{ppm} \text { with } \\
\text { simultaneous } \\
\text { symptoms of LI }\end{array}$ \\
\hline$>18$ & $\begin{array}{l}\text { Self-assessed lactos } \\
\text { maldigestion; } \\
\text { willingness to } \\
\text { participate in all } \\
\text { test days }\end{array}$ \\
\hline
\end{tabular}

Exclusion criteria

\section{IBD; pancreatic exocrine insufficiency; chronic diseases; diagnosis of} cancer; use of probiotics and antibiotics in the last 3 weeks

Organic GI diseases (as IBD); pregnancy; abdominal surgery in the previous 6 months; infective diseases; drug or alcohol abuse; metabolic disease; mental illness; chronic or neoplastic disease; severe heart failure

and/or GI chronic disease; acute infection/gastroenteritis at time of enrollment; allergy to cow's milk products; immunodeficiency

IBS; constipation; IBD

Congenital lactose deficiency; GI diseases (as IBD); recent nausea, vomiting, or diarrhea; pregnancy; breastfeeding; history of cancer in the last 5 years or surgery in the last 6 months

Diagnosis of cancer; IBD; previous GI surgery; allergy to milk's protein; chronic diseases; use of antibiotics, laxatives, prokinetics in the last 30 days

Self-reported symptoms of excessive severity; recent use of antibiotics; GI diseases

Participation in a clinical trial with drug or medical device in the last 30 days; surgery in the last 3 months; metabolic and/or GI diseases; alcohol or drug abuse
Effect of preparation

Reduction of intolerance symptoms (in particular bloating and flatulence); no modification of the amount of excreted hydrogen

Improvement of some GI symptoms and metabolism of intestinal microbiota

Milk with A2 $\beta$-casein attenuates symptoms; milk with A1/A2 $\beta$-casein reduces lactase activity and it worsens symptoms

Milk with A1/A2 $\beta$-casein increases GI inflammation, worsens symptoms, delays intestinal transit time, deteriorates cognitive processes; milk with only A2 does not worsen the symptoms

DDS-1 strain of L. acidophilus reduces symptoms of LI (in particular diarrhea, cramping, and vomit)

Reduction of hydrogen excreted in $40 \%$ of cases; symptom improvement in most patients (although there was no correlation between excreted hydrogen levels and symptoms)

Worsening of symptoms; no significant reduction in hydrogen excretion

\author{
Reduction of hydrogen \\ excretion peak at HBT; \\ improvement of abdominal \\ pain and flatulence
}


Table 1 (continued)

\begin{tabular}{|c|c|c|c|c|c|c|}
\hline Authors & Preparation used & $\begin{array}{l}\text { Subjects } \\
\text { [number] }\end{array}$ & $\begin{array}{l}\text { Age } \\
\text { [years] }\end{array}$ & Inclusion criteria & Exclusion criteria & Effect of preparation \\
\hline $\begin{array}{l}\text { Savaiano DA } \\
\text { et al. } 2013 \\
\text { [63] }\end{array}$ & $\begin{array}{l}\text { Galacto-oligosaccharide } \\
\quad \text { (RP-G28) }\end{array}$ & 85 & $18-64$ & $\begin{array}{l}\text { Self-reported history } \\
\text { of LI of at least } 1 \\
\text { month; HBT } \\
\text { positive }\end{array}$ & $\begin{array}{l}\text { Diabetes mellitus; disorders of } \\
\text { GI motility; IBS; IBD; } \\
\text { celiac disease; history of GI } \\
\text { surgery }\end{array}$ & $\begin{array}{l}\text { Reduction of hydrogen } \\
\text { excretion at HBT; } \\
\text { improvement of abdominal } \\
\text { pain, flatulence, cramping, } \\
\text { and bloating }\end{array}$ \\
\hline $\begin{array}{l}\text { Ojetti V et al. } \\
2010 \text { [43] }\end{array}$ & $\begin{array}{l}\text { Supplementation with } \\
\text { Lactobacillus reuteri } \\
\text { or tilactase }\end{array}$ & 60 & $18-65$ & $\begin{array}{l}\text { Symptoms of LI after } \\
\text { ingestion of } \\
\text { lactose; HBT } \\
\text { positive }\end{array}$ & $\begin{array}{l}\text { Diagnosis of small intestinal } \\
\text { bacterial overgrowth; } \\
\text { allergy to milk proteins }\end{array}$ & $\begin{array}{l}\text { Reduction of hydrogen } \\
\text { excretion at HBT (more } \\
\text { with tilactase than } \\
\text { L. reuteri); improvement of } \\
\text { abdominal pain, flatulence, } \\
\text { bloating, and diarrhea } \\
\text { (more with tilactase than } \\
\text { L. reuteri) }\end{array}$ \\
\hline $\begin{array}{l}\text { He T et al. } 2008 \\
\quad[57]\end{array}$ & $\begin{array}{l}\text { Capsules of } \\
\text { Bifidobacterium } \\
\text { longum and a yogurt } \\
\text { with a specific } \\
\text { probiotic strain } \\
\text { (Bifidobacterium } \\
\text { animalis DN173010) }\end{array}$ & 11 & $23-54$ & $\begin{array}{l}\text { Healthy subjects; } \\
\text { Lactose Challenge } \\
\text { Test 6-hour } \\
\text { Symptom Score > } \\
10\end{array}$ & $\begin{array}{l}\text { Use of antibiotics or laxatives } \\
\text { during the last } 3 \text { months }\end{array}$ & $\begin{array}{l}\text { Changes in the metabolism of } \\
\text { intestinal bacterial flora; } \\
\text { improvement of symptoms }\end{array}$ \\
\hline $\begin{array}{c}\text { Montalto et al. } \\
2005 \text { [42] }\end{array}$ & $\begin{array}{l}\text { Exogenous } \\
\text { beta-galactosidase }\end{array}$ & 30 & $18-65$ & $\begin{array}{l}\text { Symptoms of LI after } \\
\text { ingestion of } \\
\text { lactose; HBT } \\
\text { positive }\end{array}$ & $\mathrm{n} / \mathrm{a}$ & $\begin{array}{l}\text { Reduction of hydrogen } \\
\text { excretion at HBT; } \\
\text { improvement of symptoms }\end{array}$ \\
\hline
\end{tabular}

starting the study, after 35 days of taking RP-G28 or placebo and after 30 days of consumption of lactose-containing products. The study found a high efficacy of the RP-G28 in symptom reduction, demonstrated by the results obtained with HBT and the questionnaire in the patients of the group who took the product. These patients had better clinical outcomes than patients who received placebo. Therefore, this high efficacy, together with the safety of the use of this product, makes RP-G28 a valid option for lactose-intolerant patients who can consume products containing lactose without developing gastrointestinal symptoms [63]. Table 1 schematically shows the studies cited in this section.

\section{Conclusions}

On the basis of above, it is possible to state that, among the diagnostic methods available today, HBT represents the most valid choice both in terms of diagnostic accuracy and inexpensiveness. However, it would be useful to associate methane with hydrogen measurement too, so as to increase the sensitivity and specificity of the test. In fact, in this way, it is possible to identify lactose intolerance also in subjects with a bacterial flora which does not produce $\mathrm{H}_{2}$ but $\mathrm{CH}_{4}[17,18]$.

From the results obtained in the various clinical trials mentioned above, in reference to therapeutic option, it is not possible to define a standardized therapy. This is determined by the fact that the effects obtained by the administration of a certain compound are not always homogeneous, as, for example, in the case of exogenous lactase [40-44]. Instead, we should define a treatment tailored to the patient, evaluating which therapeutic options are most effective for the person in question. In general terms, it is possible to state that probiotics represent a valid strategy that has proved effective, many times, in improving the symptoms of lactose intolerance [50-56].

Availability of Data and Material Not applicable. Code Availability Not applicable.

Author Contribution Roberto CATANZARO: drafting, editing, and submitting the manuscript; Morena SCIUTO: drafting, editing, and submitting the manuscript; Francesco MAROTTA: acquisition of data and revision of the manuscript. All authors approved the final version of the manuscript.

Funding Open Access funding provided by Università degli Studi di Catania within the CRUI-CARE Agreement.

\section{Declarations}

Ethics Approval Not applicable.

Consent to Participate Not applicable. 
Consent for Publication Not applicable.

Conflicts of Interest The authors declare no competing interests.

Open Access This article is licensed under a Creative Commons Attribution 4.0 International License, which permits use, sharing, adaptation, distribution and reproduction in any medium or format, as long as you give appropriate credit to the original author(s) and the source, provide a link to the Creative Commons licence, and indicate if changes were made. The images or other third party material in this article are included in the article's Creative Commons licence, unless indicated otherwise in a credit line to the material. If material is not included in the article's Creative Commons licence and your intended use is not permitted by statutory regulation or exceeds the permitted use, you will need to obtain permission directly from the copyright holder. To view a copy of this licence, visit http://creativecommons.org/licenses/by/4.0/.

\section{References}

1. Vandenplas Y. Lactose intolerance. Asia Pac J Clin Nutr. 2015;24: S9-S13.

2. Rosado JL. Lactose intolerance. Gac Med Mex. 2016;152:67-73.

3. Storhaug CL, Fosse SK, Fadnes LT. Country, regional, and global estimates for lactose malabsorption in adults: a systematic review and meta-analysis. Lancet Gastroenterol Hepatol. 2017;2:738-46.

4. Deng Y, Misselwitz B, Dai N, Fox M. Lactose intolerance in adults: biological mechanism and dietary management. Nutrients. 2015;7: 8020-35.

5. Ugidos-Rodríguez S, Matallana-González MC, Sánchez-Mata MC. Lactose malabsorption and intolerance: a review. Food Funct. 2018;9:4056-68.

6. Lomer MC, Parkes GC, Sanderson JD. Review article: lactose intolerance in clinical practice - myths and realities. Aliment Pharmacol Ther. 2008;27:93-103.

7. Wilder-Smith $\mathrm{CH}$, Olesen SS, Materna A, Drewes AM. Fermentable sugar ingestion, gas production, and gastrointestinal and central nervous system symptoms in patients with functional disorders. Gastroenterology. 2018;155:1034-44.

8. Misselwitz B, Butter M, Verbeke K, Fox MR. Update on lactose malabsorption and intolerance: pathogenesis, diagnosis and clinical management. Gut. 2019;68:2080-91.

9. Bayless TM, Brown E, Paige DM. Lactase non-persistence and lactose intolerance. Curr Gastroenterol Rep. 2017;19:23.

10. Hassan HY, van Erp A, Jaeger M, Tahir H, Oosting M, Joosten L, et al. Genetic diversity of lactase persistence in East African population. BMC Res Notes. 2016;9:8.

11. Labrie V, Buske OJ, Oh E, Jeremian R, Ptak C, Gasiünas, et al. Lactase non-persistence is directed by DNA variation-dependent epigenetic aging. Nat Struct Mol Biol. 2016;23:556-73.

12. Szilagyi A, Ishayek N. Lactose intolerance, dairy avoidance, and treatment options. Nutrients. 2018;10:1994.

13. Zhu Y, Zheng X, Cong Y, Chu H, Fried M, Dai N, et al. Bloating and distention in irritable bowel syndrome: the role of gas production and visceral sensation after lactose ingestion in a population with lactase deficiency. Am J Gastroenterol. 2013;108:1516-25.

14. Schiffner R, Kostev K, Gothe H. Do patients with lactose intolerance exhibit more frequent comorbidities than patients without lactose intolerance? An analysis of routine data from German medical practices. Ann Gastroenterol. 2016;29:174-9.

15. Swagerty DL Jr, Walling AD, Klein RM. Lactose intolerance. Am Fam Physician. 2002;65:1845-50.
16. Yang JF, Fox M, Chu H, Zheng X, Long YQ, Pohl D, et al. Foursample lactose hydrogen breath test for diagnosis of lactose malabsorption in irritable bowel syndrome patients with diarrhea. World J Gastroenterol. 2015;21:7563-70.

17. Houben E, De Preter V, Billen J, Van Ranst M, Verbeke K. Additional value of $\mathrm{CH}_{4}$ measurement in a combined ${ }^{13} \mathrm{C} / \mathrm{H}_{2}$ lactose malabsorption breath test: a retrospective analysis. Nutrients. 2015;7:7469-85.

18. Rojo C, Jaime F, Azócar L, Hernández C, Villagrán A, Miquel JF, et al. Concordance between Lactose Quick Test, hydrogen-methane breath test and genotyping for the diagnosis of lactose malabsorption in children. Neurogastroenterol Motil. 2018;30:e13271.

19. Braden B. Methods and functions: Breath tests. Best Pract Res Clin Gastroenterol. 2009;23:337-52.

20. Shin W. Medical applications of breath hydrogen measurements. Anal Bioanal Chem. 2014;406:3931-9.

21. Levitt MD, Hirsh P, Fetzer CA, Sheahan M, Levine AS. $\mathrm{H}_{2}$ excretion after ingestion of complex carbohydrates. Gastroenterology. 1987;92:383-9.

22. Volpe M, Scaldaferri F, Ojetti V, Poscia A. Breath tests sustainability in hospital settings: cost analysis and reimbursement in the Italian National Health System. Eur Rev Med Pharmacol Sci. 2013;17:99-104.

23. Gasbarrini A, Corazza GR, Gasbarrini G, Montalto M, Di Stefano M, Basilisco G, et al. Methodology and indications of $\mathrm{H}_{2}$-breath testing in gastrointestinal diseases: the Rome Consensus Conference. Aliment Pharmacol Ther. 2009;29:1-49.

24. Kuokkanen M, Enattah NS, Oksanen A, Savilahti E, Orpana A, Järvelä I. Transcriptional regulation of the lactase-phlorizin hydrolase gene by polymorphisms associated with adult-type hypolactasia. Gut. 2003;52:647-52.

25. Santonocito C, Scapaticci M, Guarino D, Annicchiarico EB, Lisci $\mathrm{R}$, Penitente $\mathrm{R}$, et al. Lactose intolerance genetic testing: is it useful as routine screening? Results on 1426 south-central Italy patients. Clin Chim Acta. 2015;439:14-7.

26. Tomczonek-Moruś J, Wojtasik A, Zeman K, Smolarz B, BąkRomaniszyn L. 13910C >T and 22018G >A LCT gene polymorphisms in diagnosing hypolactasia in children. United European Gastroenterol J. 2019;7:210-6.

27. Kuokkanen M, Myllyniemi M, Vauhkonen M, Helske T, Kääriäinen I, Karesvuori S, et al. A biopsy-based quick test in the diagnosis of duodenal hypolactasia in upper gastrointestinal endoscopy. Endoscopy. 2006;38:708-12.

28. Ojetti V, La Mura R, Zocco MA, Cesaro P, De Masi E, La Mazza A, et al. Quick test: a new test for the diagnosis of duodenal hypolactasia. Dig Dis Sci. 2008;53:1589-92.

29. Perets TT, Shporn E, Aizic S, Kelner E, Levy S, Bareli Y, et al. A diagnostic approach to patients with suspected lactose malabsorption. Dig Dis Sci. 2014;59:1012-6.

30. Mattar R, Basile-Filho A, Kemp R, dos Santos JS. Comparison of Quick Lactose Intolerance Test in duodenal biopsies of dyspeptic patients with single nucleotide polymorphism LCT-13910C $>$ T associated with primary hypolactasia/lactase-persistence. Acta Cir Bras. 2013;28:77-82.

31. Domínguez-Jiménez JL, Fernández-Suárez A, Ruiz-Tajuelos S, Puente-Gutiérrez JJ, Cerezo-Ruiz A. Lactose tolerance test shortened to 30 minutes: an exploratory study of its feasibility and impact. Rev Esp Enferm Dig. 2014;106:381-5.

32. Ghoshal UC, Kumar S, Chourasia D, Misra A. Lactose hydrogen breath test versus lactose tolerance test in the tropics: does positive lactose tolerance test reflect more severe lactose malabsorption? Trop Gastroenterol. 2009;30:86-90.

33. Hermida C, Corrales G, Martínez-Costa $\mathrm{OH}$, Fernández-Mayoralas A, Aragón JJ. Noninvasive evaluation of intestinal lactase with 4galactosylxylose: comparison with 3- and 2-galactosylxylose and optimization of the method in rats. Clin Chem. 2006;52:270-7. 
34. Monsalve-Hernando C, Crespo L, Ferreiro B, Martín V, Aldeguer $\mathrm{X}$, Opio $\mathrm{V}$, et al. Phase IV noninferiority controlled randomized trial to evaluate the impact on diagnostic thinking and patient management and the test-retest reproducibility of the Gaxilose test for hypolactasia diagnosis. Medicine (Baltimore). 2018;97:e13136.

35. Aragón JJ, Hermida C, Martínez-Costa OH, Sánchez V, Martín I, Sánchez JJ, et al. Noninvasive diagnosis of hypolactasia with 4Galactosylxylose (Gaxilose): a multicentre, open-label, phase IIBIII nonrandomized trial. J Clin Gastroenterol. 2014;48:29-36.

36. Domínguez Jiménez JL, Fernández Suárez A, Muñoz Colmenero AÚ, Fatela Cantillo D, López PI. Primary hypolactasia diagnosis: comparison between the gaxilose test, shortened lactose tolerance test, and clinical parameters corresponding to the C/T-13910 polymorphism. Clin Nutr. 2017;36:471-6.

37. Rozenberg S, Body JJ, Bruyère $\mathrm{O}$, Bergmann $\mathrm{P}$, Brandi ML, Cooper $\mathrm{C}$, et al. Effects of dairy products consumption on health: benefits and beliefs - a commentary from the Belgian Bone Club and the European Society for clinical and Economic Aspects of Osteoporosis, Osteoarthritis and Musculoskeletal Diseases. Calcif Tissue Int. 2016;98:1-17.

38. Silanikove N, Leitner G, Merin U. The interrelationships between lactose intolerance and the modern dairy industry: global perspectives in evolutional and historical backgrounds. Nutrients. 2015;7: 7312-31.

39. Montalto M, Curigliano V, Santoro L, Vastola M, Cammarota G, Manna R, et al. Management and treatment of lactose malabsorption. World J Gastroenterol. 2006;12:187-91.

40. Francesconi CF, Machado MB, Steinwurz F, Nones RB, Quilici FA, Catapani WR, et al. Oral administration of exogenous lactase in tablets for patients diagnosed with lactose intolerance due to primary hypolactasia. Arq Gastroenterol. 2016;53:228-34.

41. Di Rienzo T, D'Angelo G, D'Aversa F, Campanale MC, Cesario V, Montalto M, et al. Lactose intolerance: from diagnosis to correct management. Eur Rev Med Pharmacol Sci. 2013;17:18-25.

42. Montalto M, Nucera G, Santoro L, Curigliano V, Vastola M, Covino M, et al. Effect of exogenous beta-galactosidase in patients with lactose malabsorption and intolerance: a crossover doubleblind placebo-controlled study. Eur J Clin Nutr. 2005;59:489-93.

43. Ojetti V, Gigante G, Gabrielli M, Ainora ME, Mannocci A, Lauritano EC, et al. The effect of oral supplementation with Lactobacillus reuteri or tilactase in lactose intolerant patients: randomized trial. Eur Rev Med Pharmacol Sci. 2010;14:163-70.

44. Ibba I, Gilli A, Boi MF, Usai P. Effects of exogenous lactase administration on hydrogen breath excretion and intestinal symptoms in patients presenting lactose malabsorption and intolerance. Biomed Res Int. 2014;2014:680196.

45. Pal S, Woodford K, Kukuljan S, Ho S. Milk intolerance, betacasein and lactose. Nutrients. 2015;7:7285-97.

46. Ho S, Woodford K, Kukuljan S, Pal S. Comparative effects of A1 versus A2 beta-casein on gastrointestinal measures: a blinded randomized cross-over pilot study. Eur J Clin Nutr. 2014;68:9941000 .

47. Jianqin S, Leiming X, Lu X, Yelland GW, Ni J, Clarke AJ. Effects of milk containing only $\mathrm{A} 2$ beta casein versus milk containing both $\mathrm{A} 1$ and $\mathrm{A} 2$ beta casein proteins on gastrointestinal physiology, symptoms of discomfort, and cognitive behavior of people with self-reported intolerance to traditional cows' milk. Nutr J. 2016;15:35.

48. He M, Sun J, Jiang ZQ, Yang YX. Effects of cow's milk betacasein variants on symptoms of milk intolerance in Chinese adults: a multicentre, randomized controlled study. Nutr J. 2017;16:72.
49. Mummah S, Oelrich B, Hope J, Vu Q, Gardner CD. Effect of raw milk on lactose intolerance: a randomized controlled pilot study. Ann Fam Med. 2014;12:134-41.

50. Shi LH, Balakrishnan K, Thiagarajah K, Mohd Ismail NI, Y in OS. Beneficial properties of probiotics. Trop Life Sci Res. 2016;27:7390.

51. Saarela M, Mogensen G, Fondén R, Mättö J, Mattila-Sandholm T. Probiotic bacteria: safety, functional and technological properties. J Biotechnol. 2000;84:197-215.

52. Kligler B, Cohrssen A. Probiotics. Am Fam Physician. 2008;78: 1073-8.

53. Wilkins T, Sequoia J. Probiotics for gastrointestinal conditions: a summary of the evidence. Am Fam Physician. 2017;96:170-8.

54. Pakdaman MN, Udani JK, Molina JP, Shahani M. The effects of the DDS-1 strain of lactobacillus on symptomatic relief for lactose intolerance - a randomized, double-blind, placebo-controlled, crossover clinical trial. Nutr J. 2016;15:56.

55. Gingold-Belfer R, Levy S, Layfer O, Pakanaev L, Niv Y, Dickman $\mathrm{R}$, et al. Use of a novel probiotic formulation to alleviate lactose intolerance symptoms - a pilot study. Probiotics Antimicrob Proteins. 2020;12:112-8.

56. Vitellio P, Celano G, Bonfrate L, Gobbetti M, Portincasa P, De Angelis M. Effects of Bifidobacterium longum and Lactobacillus rhamnosus on gut microbiota in patients with lactose intolerance and persisting functional gastrointestinal symptoms: a randomised, double-blind, cross-over study. Nutrients. 2019;11:886.

57. He T, Priebe MG, Zhong Y, Huang C, Harmsen HJ, Raangs GC, et al. Effects of yogurt and bifidobacteria supplementation on the colonic microbiota in lactose-intolerant subjects. J Appl Microbiol. 2008;104:595-604.

58. de Vrese M, Laue C, Offick B, Soeth E, Repenning F, Thoß A, et al. A combination of acid lactase from Aspergillus oryzae and yogurt bacteria improves lactosedigestion in lactose maldigesters synergistically: a randomized, controlled, double-blind cross-over trial. Clin Nutr. 2015;34:394-9.

59. Rastall RA, Gibson GR. Recent developments in prebiotics to selectively impact beneficial microbes and promote intestinal health. Curr Opin Biotechnol. 2015;32:42-6.

60. Roberfroid M, Gibson GR, Hoyles L, McCartney AL, Rastall R, Rowland I, et al. Prebiotic effects: metabolic and health benefits. $\mathrm{Br}$ J Nutr. 2010;104:S1-S63.

61. Torres DPM, Gonçalves MDPF, Teixeira JA, Rodrigues LR. Galacto-Oligosaccharides: production, properties, applications, and significance as prebiotics. Compr Rev Food Sci Food Saf. 2010;9:438-54.

62. Gibson GR, Hutkins R, Sanders ME, Prescott SL, Reimer RA, Salminen $\mathrm{S}$, et al. Expert consensus document: The International Scientific Association for Probiotics and Prebiotics (ISAPP) consensus statement on the definition and scope of prebiotics. Nat Rev Gastroenterol Hepatol. 2017;14:491-502.

63. Savaiano DA, Ritter AJ, Klaenhammer TR, James GM, Longcore AT, Chandler JR, et al. Improving lactose digestion and symptoms of lactose intolerance with a novel galacto-oligosaccharide (RPG28): a randomized, double-blind clinical trial. Nutr J. 2013;12: 160.

Publisher's Note Springer Nature remains neutral with regard to jurisdictional claims in published maps and institutional affiliations. 